\title{
ANALISA PENGARUH PENDELEGASIAN SEBAGIAN KEWENANGAN BUPATI TERHADAP EFEKTIVITAS KINERJA KECAMATAN DI KABUPATEN SIDOARJO
}

\section{Hasan Ubaidillah}

Fakultas Bisnis, Hukum dan IImu Sosial, Universitas Muhammadiyah Sidoarjo, Indonesia

This study concerns the delegation of part of the Regent's authority which in its implementation affects the performance of the district in Sidoarjo regency. By using a qualitative approach, this study describes the effectiveness of performance as seen from the implementation of activities and human capacity. The results showed that the policy of delegating the authority of the Regent to the District Head in Sidoarjo Regency was still not optimal. Apart from the implementation of delegation which is still administrative in nature and uses a uniform pattern in each sub-district without considering the potential character of the sub-district.

Keywords: Delegation, authority and effectiveness.

OPEN ACCESS

ISSN 2528-4649 (online) ISSN 2338-4409 (print)

Reviewed by: Asat Rizal \& Zarah Puspitaningtyas \& Eko Purwanto

${ }^{*}$ Correspondence:

Received: 25 Juli 2020 Accepted: 28 Agustus 2020 Published: 30 September 2020

\section{Citation:}

Ubaidillah H (2020) ANALISA PENGARUH PENDELEGASIAN SEBAGIAN KEWENANGAN BUPATI TERHADAP EFEKTIVITAS KINERJA

KECAMATAN DI KABUPATEN SIDOARJO. JBMP. 6:2.

doi: 10.21070/jbmp.v6i2.940
Penelitian ini mengenai pendelegasian sebagian kewenangan Bupati yang dalam implementasinya berpengaruh pada efektivitas kinerja kecamatan di kabupaten Sidoarjo. Dengan menggunakan pendekatan kualitatif, penelitian ini mendiskripsikan tentang efektifitas kinerja yang dilihat dari pelaksanaan kegiatan dan kapasitas sumberdaya manusia. Hasil penelitian menunjukkan bahwa kebijakan pendelegasian sebagian kewenangan Bupati kepada Camat di Kabupaten Sidoarjo masih kurang optimal. Selain dari pelaksanaan pendelegasian yang masih bersifat adminitratif dan menggunakan pola penyeragaman dimasing masing kecamatan tanpa mempertimbangkan perbedaan potensi karakter kecamatan.

Kata Kunci : Pendelegasian, wewenang dan efektifitas. 


\section{PENDAHULUAN}

Pelaksanaan desentralisasi di Kabupaten/Kota merupakan persoalan yang sangat penting dan memerlukan pengkajian secara sistematik. Salah satu aspek desentralisasi yang tengah berlangsung di Kabupaten/Kota adalah mengenai pelimpahan kewenangan dari Bupati/Walikota kepada Camat. Menurut Stoner dalam Rifly Kesumanjaya (2010) pendelegasian wewenang adalah pelimpahan wewenang formal dan tanggung jawab kepada seorang bawahan untuk menyelesaikan aktivitas tertentu.

Pemerintah Daerah dalam era otonomi daerah dan desentralisasi saat ini, memerlukan sumber-sumber yang memadai untuk melaksanakan kewenangan yang telah diserahkan/dilimpahkan. Oleh karena itu, birokrasi di tingkat kecamatan menempati posisi yang sangat penting dalam penyelenggaraan urusan yang dilimpahkan dari Bupati, walaupun di satu sisi kemampuan anggaran keuangan Pemerintah Daerah cenderung terbatas. Undang-Undang Nomor 23 Tahun 2014 mengatur kewenangan pemerintahan daerah dalam menyelenggarakan urusan pemerintahan serta kewenangan yang dikecualikan yang menjadi kewenangan pemerintah pusat.

Pemerintah kecamatan merupakan salah satu instansi pemerintah daerah yang langsung melaksanakan pelayanan kepada masyarakat. Terkait dengan hal tersebut, Wasistiono (2002) mengatakan bahwa pemerintah kecamatan dapat dijadikan sebagai "pusat pelayanan". Untuk mendukung hal tersebut, maka melalui implementasi kebijakan otonomi daerah telah mendorong terjadinya suatu perubahan yang sangat penting pada kecamatan yaitu menyangkut kedudukan, tugas pokok, dan fungsi kecamatan yang sebelumnya merupakan perangkat wilayah dalam azaz dekonsentrasi, berubah status menjadi perangkat daerah yang dalam kerangka azas desentralisasi.

Secara implementatif Kabupaten Sidoarjo sudah menetapkan kewenangan-kewenangan apa saja yang telah dilimpahkan kewenangannya kepada camat sesuai dengan Peraturan Bupati Sidoarjo Nomor 4 Tahun 2019 terdapat 11 (sebelas) bidang kewenangan yang dilimpahkan kepada camat. Pelimpahan sebagian wewenang dari Bupati Sidoarjo kepada Camat harus dievaluasi sebagai bagian untuk menemukan problema dan solusi untuk perbaikan dan afektifitas penyelenggaraan pemerintahan daerah di Kabupaten Sidoarjo.

\section{RUMUSAN MASALAH}

Berdasarkan uraian di atas, peneliti merumuskan masalah sebagai berikut :

1. Bagaimana efektifitas Implementasi Kebijakan pelimpahan sebagian kewewenangan pemerintahan dari Bupati kepada Camat di Kabupaten Sidoarjo?

2. Faktor-faktor apa saja yang menjadi penghambat dalam Implementasi Kebijakan pelimpahan sebagian kewewenangan pemerintahan dari Bupati kepada Camat di Kabupaten
Sidoarjo?

3. Upaya apa saja yang harus dilakukan dalam mengatasi hambatan Implementasi Kebijakan pelimpahan sebagian kewewenangan pemerintahan dari Bupati kepada Camat di Kabupaten Sidoarjo?

\section{TUJUAN}

Tujuan dari penelitian ini dirumuskan sebagai berikut.

1. Teridentifikasikannya sebagian kewenangan pemerintahan yang dapat atau perlu dilimpahkan kepada kecamatan sebagai upaya penguatan otonomi daerah

2. Teridentifikasikannya kesiapan kecamatan dalam menerima dan menjalankan sebagian kewenangan pemerintahan yang dilimpahkan.

3. Teridentifikasikannya kebijakan, tahapan, kebutuhan sumber daya, serta faktor-faktor penentu keberhasilan pelimpahan sebagian kewenangan pemerintahan kepada kecamatan.

\section{METODE PENELITIAN}

Desain yang digunakan dalam penelitian ini adalah disain deskriptif dengan pola pendekatan kualitatif-induktif. Bogdan dan Taylor (Basrowi \& Suwandi, 2008:1), menyatakan bahwa "penelitian kualitatif adalah salah satu prosedur penelitan yang menghasilkan data deskriptif berupa ucapan atau tulisan dan perilaku orang-orang yang diamati”. Melalui penelitian kualitatif peneliti dapat mengenali subyek, merasakan apa yang mereka alami dalam kehidupan sehari-hari.

Lokasi penelitian di tetapkan di 18 (delapan belas) Kecamatan di wilayah Kabupaten Sidoarjo. Teknik pengumpulan data dalam penelitian ini menggunakan data primer berupa instrument yang terdiri dari pedoman wawancara dan kuisioner. Wawancara di lakukan dengan responden terpilih dan responden yang di tentukan melalui purposive sample yaitu, Sekda, Assisten Sekda, Kepala Dinas, Camat. Selanjutnya, metode kualitatif dalam penelitian ini akan menggunakan tiga langkah dalam menganalisa data, yaitu reduksi data, penyajian data dan penarikan kesimpulan.

\section{HASIL DAN PEMBAHASAN}

Sesuai dengan PP No. 17 Tahun 2018 tentang Kecamatan, bahwa camat dapat dilimpahkan sebagian kewenagan urusan pemerintahan daerah. Pelimpahan sebagian kewenangan urusan pemerintahan dari Bupati kepada Camat mencakup urusan pemerintahan pada pelayanan perizinan dan nonperizinan. Terkait dengan pelayanan perizinan dilaksanakan melalui pelayanan terpadu serta pengembangan inovasi dengan kriteria, proses sederhana, objek perizinan berskala kecil, 
tidak memerlukan kajian teknis yang kompleks; dan tidak memerlukan teknologi tinggi. Pelayanan nonperizinan yang dilimpahkan kepada Camat berdasarkan pada kriteria berkaitan dengan pengawasan terhadap objek perizinan, kegiatan bersekala kecil dan pelayanan langsung pada masyarakat yang bersifat rutin. Pelimpahan juga didasarkan pada pemetaan pelayanan publik sesuai dengan karakteristik Kecamatan dan/ atau kebutuhan masyarakat setempat.

Beberapa keuntungan yang diperoleh dengan adanya pelimpahan urusan (transfer of power) dari pemerintah kabupaten kepada kecamatan, antara lain beban Pemda dalam penyediaan/ pemberian layanan semakin berkurang karena telah diambil alih oleh kecamatan sebagai ujung tombak pelayanan, pemda tidak perlu membentuk kelembagaan yang besar sehingga dapat menghemat anggaran, alokasi dan distribusi anggaran lebih merata keseluruh wilayah, dapat menjadi stimulan bagi pemerataan pembangunan dan pertumbuhan ekonomi regional, pelimpahan kewenangan ini juga sebagai wahana pemberdayaan fungsi kecamatan yang selama ini terabaikan.

\section{Analisa Implementasi Kebijakan}

Kabupaten Sidoarjo, tentunya memerlukan suatu kondisi yang kondusif untuk mendorong laju pertumbuhan ekonominya yang dapat dilakukan dengan mendorong dunia usaha dan investasi di daerah agar dapat tumbuh dan berkembang secara berkesinambungan. Untuk melakukan hal tersebut pemerintah Kabupaten Sidoarjo harus mampu memberikan pelayanan yang terbaik kepada masyarakat yang tentu saja melalui berbagai kemudahan kemudahan termasuk kemudahan dalam mendapatkan pelayanan dan informasi.

Pelayanan publik (public services) oleh birokrasi publik dimaksudkan untuk mensejahterakan masyarakat (warga negara) dari suatu negara kesejahteraan (welfarestate). Implementasi kebijakan kewenangan dari Bupati yang dilimpahkan kepada Camat sebagai wujud dan usaha pemerintah Kabupaten Sidoarjo untuk lebih mendekatkan pelayanan kepada masyarakatnya. Peraturan Bupati Nomor 4 Tahun 2019 yang melimpahkan 11 (sebelas) bidang kewenangan kepada Camat merupakan sebuah kepercayaan Bupati kepada Camat untuk melaksanakan kewenangan yang dimilikinya.

Seperti dikemukakan oleh T. Hani Handoko (2007), mengatakan bahwa "wewenang (authority) adalah hak untuk melakukan sesuatu atau memerintah orang lain untuk melakukan atau tidak melakukan sesuatu agar tercapai tujuan tertentu". Berdasarkan pernyataan di atas, dapat diketahui bahwa perlunya pendelegasian agar proses pelaksanaan kerja oleh pegawai dapat berjalan dengan efekti. Pola pendelegasian yang seragam tidak akan berjalan dengan efektif, baik dari segi dana, sarana dan sumber daya lainnya sehingga akan menimbulkan pemborosan dan pembengkakan anggaran, hal ini dikarenakan kemungkinan kewenangan yang didelegasikan tidak tepat dan tidak sesuai dengan kebutuhan di kecamatan tersebut. Berpijak pada Peraturan Bupati tentang pelimpahan sebagian kewenangan di kabupaten Sidoarjo kepada camat, apabila di lihat dari pola pelimpahannya cenderung seragam.

Pelimpahan wewenang dari Bupati kepada Camat ini seharusnya lebih diarahkan pada fungsi-fungsi pelayanan dasar bagi masyarakat sesuai dengan tuntutan kepentingan, kebutuhan dan aspirasi masyarakat setempat.

Pendelegasian kewenangan harus mampu menjadi pengungkit kegiatan ekonomi masyarakat sehingga menjadi lebih produktif. Dengan perkataan lain, pendelegasian kewenangan jangan sampai memperpanjang jenjang birokrasi dan menciptakan ekonomi biaya tinggi yang membuat masyarakat menjadi tidak produktif dan kalah bersaing. Pelimpahan kewenangan dilakukan dengan menganut prinsip berurutan berdasarkan hierarkhi jabatan. Prinsip ini berkaitan dengan prinsip jenjang kewenangan, artinya kewenangan didelegasikan secara satu tahap demi satu tahap berdasarkan tingkat kewenangan yang dimiliki pejabat atau satu unit organisasi tertentu.

\section{Analisa Efektifitas}

Kecamatan yang selama ini lebih banyak berperan pada fungsi administratif koordinasi dalam kerangka asas dekonsentrasi telah berubah status menjadi perangkat wilayah dalam koridor asas desentralisasi. Untuk itu, Kecamatan sebagai perangkat daerah Kabupaten serta untuk lebihmemfungsikan jajarannya dalam memberikan pelayanan publik yang lebih baik, maka diperlukan fungsi/ peran delegatif dari Bupati untuk menangani sebagian urusan otonomi daerah. Menyadari hal tersebut, Kabupaten Sidoarjo telah melaksanakan pelimpahan sebagian urusan bupati kepada kecamatan dengan tujuan mendekatkan serta memberi kemudahan pelayanan kepada masyarakat ditingkat yang kecamatan. Sampai saat ini telah dilaksanakan pelimpahan urusan tersebut sebanyak 11 bidang dengan 40 rincian urusan berdasarkan pada Peraturan Bupati Nomor 4 Tahun 2019. Namun, pola pelimpahan ini masih memberlakukan konsep keseragaman untuk 18 kecamatan yang ada dikabupaten ini tanpa mencermati potensi lokal daerah serta kebutuhan di tingkat kecamatan.

Perlu disadari bahwa pelimpahan urusan ini membutuhkan kesiapan sumberdaya (SDM aparatur, sarana dan prasarana, serta anggaran) pada tingkat kecamatan itu sendiri. Selain itu, tentunya pelimpahan sebagian urusan yang diberikan kepada kecamatan ini dilakukan berdasarkan kriteria efisiensi. Kriteria efisiensi adalah kriteria pelimpahan urusan pemerintahan dengan memperhatikan daya guna tertinggi yang dapat diperoleh dari penyelenggaraan suatu urusan pemerintahan di lingkup kecamatan. Apabila urusan pemerintahan lebih berdayaguna ditangani oleh kecamatan, maka urusan tersebut menjadi kewenangan camat.

Analisis tingkat keefektifan pelaksanaan kewenangan tersebut ke dalam tiga kategori yaitu :

1. Urusan yang dilimpahkan telah berjalan dengan baik dan efektif Jika bidang urusan tersebut secara total angkanya 
diatas 100

2. Urusan yang dilimpahkan belum berjalan dengan efektif Jika bidang urusan tersebut secara total angkanya berada antara 1 hingga 100

3. Urusan yang tidak dapat dijalankan Jika bidang urusan tersebut angkanya 0 atau tidak terdapat kegiatan pada bidang tersebut.

[Table 1 about here.]

Berdasarkan data di atas, secara keseluruhan bidang kewenangan yang dilimpahkan telah dilaksanakan, meskipun dalam pelaksanaannya terdapat beberapa kendala yang menyebabkan belum efektifnya pelimpahan bidang kewenangan. Dari 11 bidang kewenangan yang dilimpahkan, Bidang Pemberdayaan masyarakat desa dengan 249 kegiatan tergolong paling efektif, sedang 10 bidang kewenangan yang lain dengan jumlah kegiatan dibawah 100 tergolong kurang efektif.

\section{Analisis Tentang Urgensi dan Kemampuan}

Pelimpahan sebagian kewenangan dari Bupati kepada Camat yang dituangkan ke dalam Peraturan Bupati Kabupaten Sidoarjo Nomor: 4 Tahun 2019 merupakan salah satu tindakan nyata dalam nuansa desentralisasi dan otonomi daerah. Dengan adanya pelimpahan memang dimaksudkan untuk lebih memperkuat kapasitas penyelenggaraan pemerintahan daerah di kabupaten, termasuk kecamatan.

Aspirasi dari kecamatan tentunya sangat diharapkan dalam membentuk satu kesatuan cara pandang yang dapat diterima dan disepakati bersama. Kebijakan yang dibuat saat ini tidak hanya Top Down, tetapi juga Bottom Up. Segala sesuatu yang menyangkut karakteristik, potensi, kelebihan bahkan kelemahan di kecamatan tentu hanya pihak kecamatan saja yang mengetahui. Sehingga dengan menyerap aspirasi di kecamatan akan terlihat apa saja yang menjadi kebutuhan kecamatan.

[Table 2 about here.]

Dari hasil analisis tentang urgensi dan kemampuan kecamatan dalam pelaksanaan urusan yang dilimpahkan menurut jawaban responden, maka urusan tersebut dapat dikelompokkan menjadi 4 bagian yang dimasukkan ke dalam 4 kuadran yang berbeda.

Kriteria yang dipakai dalam penentuan letak kuadran ini berdasarkan pembagian 4 kuadran.

1. Kuadran 1

2. Kuadran 2

3. Kuadran 3

4. Kuadran 4
[Table 3 about here.]

KUADRAN 1; Pelaksanaan pelimpahan urusan Kabupaten Sidoarjo kepada 18 Kecamatan telah terlaksana. Namun dalam pelaksanaannya masih sebagian dan tidak penuh. Menurut data yang telah dihimpun, terdapat 11 bidang urusan dilimpahkan berjalan di Kecamatan.

KUADRAN 2 ; Berdasarkan hasil analisis terhadap jawaban responden, tidak terdapat satupun bidang urusan yang berada pada kuadran dua ini.

KUADRAN 3 ; Terdapat dua bidang urusan yang ada pada kuadran tiga ini, yang dianggap tidak penting dan dapat diganti dengan urusan lain atau urusan baru yang dianggap lebih urgen. Kondisi ini disebabkan oleh pihak Kabupaten yang melakukan kebijakan pelimpahan urusan ini bersifat generatif atau sama untuk 18 Kecamatan di Kabupaten Sidoarjo.

KUADRAN 4 ; Berdasarkan hasil analisis terhadap jawaban responden, tidak terdapat satupun bidang urusan yang berada pada kuadran empat ini.

\section{KESIMPULAN}

Pelaksanaan pelimpahan sebagian urusan Bupati kepada Camat berdasarkan Peraturan Bupati Kabupaten Sidoarjo Nomor 9 tahun 2019 tentang Pelimpahan Pelaksanaan Sebagian Kewenangan Bupati Sidoarjo Kepada Camat di Wilayah Kabupaten Sidoarjo telah berjalan. Dari 11 urusan yang dilimpahkan, sebagian dapat diimplementasikan dengan beberapa bidang kewenangan yang belum berjalan secara optimal dalm implementasinya. Kondisi ini lebih disebabkan oleh kebijakan yang bersifat generatif serta belum mempertimbangkan aspek-aspek kondisi dan potensi daerah di masing - masing kecamatan dan memperlakukan semua kecamatan sama sehingga semua kecamatan menerima pelimpahan kewenangan yang juga sama. Pelaksanaan pendelegasian wewenang Bupati kepada Camat dalam penyelenggaraan Pemerintahan Daerah dari segi teorinya yaitu Pendelegasian wewenang dilihat dari sumbernya terdiri dari kewenangan atributif dan kewenangan delegatif. Dimana kewenangan atributif adalah kewenangan yang melekat dan diberikan kepada suatu institusi atau pejabat berdasarkan peraturan perundangundangan, sedangkan kewenangan delegatif adalah kewenangan yang berasal dari pendelegasian kewenangan dari institusi atau pejabat yang lebih tinggi tingkatannya, sedangkan pelaksanaan pendelegasian wewenang Bupati kepada Camat dalam penyelenggaraan pemerintahan daerah dari segi prakteknya yaitu Camat menerima kewenangan dari Bupati/Walikota. Serta pendelegasian wewenang dari Bupati kepada Camat diperlukan untuk meningkatkan kualitas pelayanan kepada masyarakat.

\section{REFERENSI}

Basrowi dan Suwandi. (2008). Memahami Penelitian Kualitatif. Jakarta: Rineka Cipta 
Badan Pusat Statistik Kabupaten Sidoarjo. (2019). Sidoarjo Dalam Angka Tahun 2019.

Dunn, William N. (1994). Analisis Kebijakan Publik. Yogyakarta: Gadjahmada

Handoko, T. Hani. (2007), Manajemen, Edisi II, BPFE, Yogyakarta.

Mustopadidjaya. (2002). Manajemen Proses Kebijakan Publik, Formulasi, Implementasi dan Evaluasi Kinerja. Jakarta: LAN.

Rifly Kesumanjaya. (2010). Pengaruh Pendelegasian Wewenang dan Komitmen terhadap Prestasi Kerja Karyawan pada bagian

Sumber Daya Manusia (SDM) PT. Perkebunan Nusantara IV (Persero) Medan. Skripsi, Universitas Sumatera Utara: Medan.

Sadu Wasistiono \& Irwan Tahir. (2006): Prospek Pengembangan Desa, Bandung: CV. Fokusmedia

Wahab, Abdul Solichin. (1997). Analisis Kebijaksanaan: Dari Formulasi ke Implementasi Kebijaksanaan Negara. Jakarta: Penerbit PT Bumi Aksara.

Sedarmayanti, dkk. (2005). Desentralisasi dan Tuntutan Penataan Ulang Kelembagaan Daerah. Humaniora, Bandung.

Tri Widodo W. Utomo. (2006). Penataan Kewenangan / Urusan Pemerintah Daerah, Pendelegasian (Transfer) Kewenangan, dan Alternatif Model Kelembagaan Daerah. Bahan Diskusi Disampaikan Pada "Diklat Penataan Kelembagaan Perangkat Daerah" Samarinda, 14-18 November 2006.

Conflict of Interest Statement: The author declare that the research was conducted in the absence of any commercial or financial relationships that could be construed as a potential conflict of interest.

Copyright $\odot 2020$ Ubaidillah. This is an open-access article distributed under the terms of the Creative Commons Attribution License (CC BY). The use, distribution or reproduction in other forums is permitted, provided the original author(s) and the copyright owner(s) are credited and that the original publication in this journal is cited, in accordance with accepted academic practice. No use, distribution or reproduction is permitted which does not comply with these terms. 


\section{LIST OF TABLES}

1 Analisis Penggolongan Berdasarkan Realisasi Kegiatan Sebagian Urusan Yang Diberikan Kepada Kecamatan 122

2 Persepsi Tentang Urgensi dan Kemampuan SDM Kecamatan ～. . . . . . . . . . . . . . . . . . . . . . . 123

3 Kuadran Persepsi Responden Tentang Urgensi dan Kemampuan SDM Kecamatan . . . . . . . . . . . . . . . 124 
TABLE 1 | Analisis Penggolongan Berdasarkan Realisasi Kegiatan Sebagian Urusan Yang Diberikan Kepada Kecamatan

\begin{tabular}{|c|c|c|c|}
\hline NO & BIDANG & TOTAL REALISASI KEGIATAN & TINGKAT EFEKTIFITAS \\
\hline 1 & Pemberdayaan Masyarakat Desa & 249 & Efektif \\
\hline 2 & Pekerjaan Umum dan Penataan Ruang & 14 & Kurang Efektif \\
\hline 3 & $\begin{array}{l}\text { Administrasi Kependudukan dan Pen- } \\
\text { catatan Sipil }\end{array}$ & 44 & Kurang Efektif \\
\hline 4 & Perhubungan & 6 & Kurang Efektif \\
\hline 5 & Tenaga Kerja & 17 & Kurang Efektif \\
\hline 6 & $\begin{array}{l}\text { Pemberdayaan Perempuan dan Perlin- } \\
\text { dungan anak }\end{array}$ & 26 & Kurang Efektif \\
\hline 7 & $\begin{array}{l}\text { Pengendalian Penduduk dan Keluarga } \\
\text { Berencana }\end{array}$ & 18 & Kurang Efektif \\
\hline 8 & Perindustrian & 9 & Kurang Efektif \\
\hline 9 & Perdagangan & 8 & Kurang Efektif \\
\hline 10 & $\begin{array}{l}\text { Ketentraman dan Ketertiban umum } \\
\text { serta perlindungan masyarakat }\end{array}$ & 39 & Kurang Efektif \\
\hline 11 & Lingkungan Hidup & 31 & Kurang Efektif \\
\hline
\end{tabular}


TABLE 2 | Persepsi Tentang Urgensi dan Kemampuan SDM Kecamatan

\begin{tabular}{|c|c|c|c|c|c|c|c|c|}
\hline \multirow{2}{*}{ NO } & \multirow{2}{*}{ BIDANG } & \multicolumn{4}{|c|}{ URGENSI PELIMPAHAN KEPADA CAMAT } & \multicolumn{3}{|c|}{ TINGKAT KEMAMPUAN CAMAT } \\
\hline & & Sangat penting & Penting & $\begin{array}{l}\text { Kurang/ } \\
\text { penting }\end{array}$ & tidak & Sangat mampu & $\begin{array}{l}\text { Cukup } \\
\text { mampu }\end{array}$ & $\begin{array}{l}\text { Kurang/tidak } \\
\text { mampu }\end{array}$ \\
\hline 1 & Pemberdayaan Masyarakat Desa & 18 & & & & 18 & & \\
\hline 2 & $\begin{array}{l}\text { Pekerjaan Umum dan Penataan } \\
\text { Ruang }\end{array}$ & & 12 & 6 & & 3 & 12 & 3 \\
\hline 3 & $\begin{array}{l}\text { Administrasi Kependudukan dan } \\
\text { Pencatatan Sipil }\end{array}$ & 18 & & & & 18 & & \\
\hline 4 & Perhubungan & 2 & 4 & 12 & & 3 & 14 & 1 \\
\hline 5 & Tenaga Kerja & 3 & 13 & 2 & & 1 & & 2 \\
\hline 6 & $\begin{array}{l}\text { Pemberdayaan Perempuan dan } \\
\text { Perlindungan anak }\end{array}$ & 14 & 4 & & & 16 & & \\
\hline 7 & $\begin{array}{l}\text { Pengendalian Penduduk dan } \\
\text { Keluarga Berencana }\end{array}$ & 15 & 1 & 2 & & & & 2 \\
\hline 8 & Perindustrian & & 4 & 14 & & 3 & 12 & 3 \\
\hline 9 & Perdagangan & & 3 & 15 & & & & 6 \\
\hline 10 & $\begin{array}{l}\text { Ketentraman dan Ketertiban } \\
\text { umum serta perlindungan } \\
\text { masyarakat }\end{array}$ & 16 & 2 & & & & & 3 \\
\hline 11 & Lingkungan Hidup & & 16 & 2 & & 2 & 13 & 3 \\
\hline
\end{tabular}


TABLE 3 | Kuadran Persepsi Responden Tentang Urgensi dan Kemampuan SDM Kecamatan

\begin{tabular}{l} 
KUADRAN 1 \\
\hline 1. Pemberdayaan Masyarakat dan Desa \\
2. Pekerjaan Umum dan Penataan Ruang \\
3. Administrasi Kependudukan dan Pencatatan Sipil \\
4. Pemberdayaan Perempuan dan Perlindungan Anak \\
5. Tenaga Kerja \\
6. Pengendalian Penduduk dan Keluarga Berencana \\
7. Ketentraman dan Ketertiban umum serta perlindungan masyarakat
\end{tabular}

KUADRAN 2

Tidak ada

KUADRAN 3

KUADRAN 4

1. Perindustrian

2. Perhubungan

3. Perdagangan

4. Lingkungan hidup

Tidak ada 